\title{
Framing the Right to Be Forgotten: A Transatlantic Cultural Clash? A Comparative Newspaper Analysis
}

\author{
Elisa Telesca ${ }^{1}$
}

\begin{abstract}
This research tests the presence of a difference of approaches to the Right to Be Forgotten (RTBF), as introduced in Article 17 of the General Data Protection Regulation (GDPR), in the media and public sphere. The focus is put on how European and US newspapers have framed the Right between 2010 and 2018. The objective is to understand how news media have presented and described the RTBF to their readers at the national level in Italy, the UK, and the US, and how such discourses reflect alleged cultural disparities.

The RTBF is hereby conceptualized as a multi-dimensional notion. It is argued that the Right can be seen from perspectives other than those related to free speech and privacy, as advanced by the academic literature. The umbrella concept of transparency is introduced as a new way to frame the RTBF, concerning transparency for and from the people, on an individual level. On the one hand, Article 17 GDPR refers to a right to transparency for the people, to know and access lawful online information about, in particular, public figures or criminals. The notion also entails a form of transparency from the people: individuals should be transparent about their past, in real life and online. On the other hand, the RTBF can also refer to a right to be "not fully transparent" online, or a right to non-transparency from the people. This implies that not all information should be published on the Internet, especially when it represents personal and sensitive data.
\end{abstract}

\section{Introduction}

Can the Internet be rewritten? Can information be erased, people forgotten, and events deleted from online sources? For a long time, the answer has been negative, but in January 2012 the European Union (EU) introduced the Right to Be Forgotten (RTBF) in Article 17 of the proposed General Data Protection Regulation (GDPR). The concept was subsequently renamed "right to erasure" in 2014. Within the GDPR, as entered into force on 25 May 2018, Article 17 currently addresses data controllers to erase personal data concerning the data subject, upon request of the latter, where "the personal data are no longer necessary in relation to the purposes for which they were collected or otherwise processed", the data "have been unlawfully processed", "the data subject withdraws consent" or "objects to the processing" of personal data concerning them (Regulation 2016/679, 2016, p. 43).

The introduction of such a right has sparked a vivid debate within academia, with scholars interpreting the RTBF in many different ways, either supporting or criticizing the legislation. The literature often points to a clash of cultures. Whereas the United States (US) highlights freedom of expression as enshrined in the First Amendment, Europe considers the right of privacy as a counterweight to that of free speech. From the first point of view, the RTBF is seen as a form of censorship and a tool risking to be abused by the corrupt and the powerful, while from the second one, the concept represents a watchdog of the right to privacy.

Academic and popular discourses often represent two worlds which can substantially differ. The claim that the European and US approaches in discussing the RTBF differ on the basis of clashing cultural values is omnipresent in the literature. But is this also the case in the public sphere? While only a minority of the population might read academic articles, newspapers are much more widely diffused and often

\footnotetext{
${ }^{1}$ Elisa Telesca received a Bachelor's degree in European Studies at Maastricht University Faculty of Arts and Social Sciences in July 2018. Contact: telesca.elisa@gmail.com
} 
represent the first (considered reliable) source people retrieve information from. The framing model holds that newspapers and the way they cover issues are both reflective of public opinion and a strong catalyst for the development and change of the latter.

Based on this theory, this research seeks to analyze the coverage of the RTBF by newspapers on both sides of the Atlantic, asking how have articles of US and European newspapers framed the Right to Be Forgotten since 2010. The aim is to analyze how the concept has been presented by such newspapers to their readers, reconstructing the main frames present within the news articles. This study seeks to understand whether and to what extent framing and reasoning devices used by the media in building a discourse about a particular issue reflect alleged cultural disparities. In order to reconstruct to a potential "European stance," the UK and Italy were chosen as home countries of the newspapers to analyze, together with the US press. The research holds societal relevance as the GDPR has entered into effect on 25 May 2018. Especially at this time, it is essential to analyze the ways news media have responded to Article 17 of such Regulation and how they have shaped the discourse around the RTBF. No previous studies have analyzed the coverage of the RTBF in newspapers, nor have used framing as a method in studying this issue.

To answer effectively such a puzzle, this study formulates four sub-questions. The first subquestion asks the extent to which Italian, UK, and US newspapers have differed in the frames adopted to discuss the RTBF. In order to obtain a more comprehensive picture of newspaper discourses, a second sub-question enquires the extent to which articles of quality and middle-market newspapers have differed in framing the RTBF. For this reason, one newspaper of each type was chosen for the three countries selected. This paper seeks to contribute to the literature by exploring under which perspectives the RTBF has been discussed within news media, apart from the right to free speech and privacy. A third subquestion guiding this study is thus to what extent are these two frames used to cover the issue.

The RTBF is hereby conceptualized as a multi-dimensional notion, which can be seen under different, varying lights. Within the literature, the RTBF has been either supported or denounced also concerning other issues, but on a much smaller scale. The fourth and last sub-question thus asks the extent to which the academic literature and the media differ in the ways they frame the RTBF. The articles were studied in depth in order to derive other possible frames and approaches used by newspapers to discuss the RTBF. In particular, this research seeks to introduce a new way to frame the RTBF which was not found in the literature, i.e., under the umbrella concept of transparency.

This paper is structured as follows. The first chapter introduces the link between the RTBF and the right to (non-)transparency. The second and third chapters explain framing as the utilized method of data analysis, as well as the employed methods of case selection, data collection and analysis. The fourth chapter presents the data collected by discussing separately each reconstructed frame. The fourth chapter examines and compares the main findings. The concluding chapter returns to the research question, summarizes the results and draws further considerations.

\section{The Right to Be Forgotten and the right to (non-) transparency}

This research seeks to engage the concept of transparency as a way to frame the RTBF. Etymologically, transparency comes from medieval Latin transparentia, i.e., "shining through". According to Google Ngram $V_{i e w e r}{ }^{2}$ the use of the word started to grow exponentially in books since the 1980s. This is because the term began to be connected with political concepts such as accountability and openness, being currently

\footnotetext{
2 https://books.google.com/ngrams/

Marble

2 Research

Papers
} 
defined by Encyclopedia Britannica as the "capacity of outsiders to obtain valid and timely information about the activities of government or private organizations" (Johnston, 2014). As the global anti-corruption movement was growing precisely in the 1980s, together with the post-war democratization and reform wave, transparency became a key governance concept. This link with democracy and liberalism is shown by the fact that transparent political processes are seen as more accountable and democratic, while freemarket processes are seen as facilitated by economic transparency. Transparency is thus nowadays considered as fundamental and integral to many political and business objectives (Johnston, 2014). These considerations conceptualize transparency as having an instrumental value, in the service of effectivity, accountability, fairness, and legitimacy, as claimed by Heald (2006). However, the concept can also be seen as also having an absolute value and as a fundamental human right (Birkinshaw, 2006).

Transparency is relevant to the RTBF debate as it concerns the interplay between a right to privacy and a right to access lawful information online. Within the RTBF literature, such a linkage is briefly mentioned only by Bernal (2014), who draws a parallel between Bambauer's (2014) data-based argument and that on the benefits of a "transparent" society (as in Brin (1998) and Bell \& Gemmell (2009)). The latter argue that the advantages gained by the openness of data outweigh the drawbacks caused by the loss of privacy, and that people should consequently embrace such transparency.

This study seeks to conceptualize transparency in a twofold manner. First, transparency refers to a right to know, mainly but not only, information about public figures (such as politicians) and institutions. In order for the latter to be held accountable, accurate and truthful information concerning them should be published and publicly available. As the Internet has grown to be the biggest source of information for the public, such information should be easily accessible also online. However, the RTBF could give the power to individuals and institutions to erase such legitimate records, depriving citizens of their right to get informed and to have an appropriate image of individuals and/or institutions that correspond to reality.

Second, the right to privacy also corresponds to a right to be "not fully transparent" online. This implies that not all information should be published on the Internet, especially when it risks hurting the reputation of individuals, or merely when it concerns their private sphere. Therefore, this regards transparency of public figures rather than of institutions. In sum, this study connects the concept of transparency with the right to know and to freedom of information. The concept of non-transparency is connected to the right to privacy. The following chapter presents the framing model and its main features.

\section{Framing: selection, salience, and culture}

Framing broadly refers to the way in which media or the public present a certain issue or topic (Reese, 2001), and it is a method of analysis particularly relevant for studies concerning issues that can be interpreted in different ways and viewed from multiple perspectives (Chong \& Druckman, 2007). This is indeed the case of the RTBF, which can be associated with a vast array of issues and concepts. To frame is the attempt to "select some aspects of a perceived reality and make them more salient in a communicating text" (Entman, 1993, p. 52). As such, frames can be defined as "conceptual tools which media and individuals rely on to convey, interpret, and evaluate information" (Neuman et al., 1992, p. $60)$.

This paper follows the emphasis put by Van Gorp (2007) in the existence of a strong connection between frames and culture. Culture is hereby referred to as an array of cultural phenomena beliefs, values, norms and so on, which are specific to a society or group. On the basis of this consideration, Van Gorp (2007) introduces the notion of a cultural stock of frames, arguing that media authors apply and emphasize such cultural phenomena in media content and present them to their readers. These phenomena then resonate in the latter as cultural values, norms, and beliefs are assumed to be shared by a whole 
population. Because of this cultural stock of frames, media authors have alternatives to consider when deciding how to frame an issue, and thus many different definitions of topics can result (Van Gorp, 2007, p. 62). A frame can therefore be seen as "an invitation or an incentive to read a news story in a particular way" (p. 63).

Framing is one of the most cited models of media effects on public opinion. It therefore presupposes the existence of senders and receivers of the "communicating texts," and often the model is applied to the study of both sides. However, this study primarily merely aims to trace the frames utilized in the selected news articles, excluding the study of a possible influence of such news content on public opinion. Therefore, the focus is put exclusively on the senders of the media text and on the process, they engage in when framing issues, also called "frame-building" (Scheufele, 1999).

Van Gorp (2007) refers to each frame that the sender has applied in a communicating text as a "frame package," i.e. "a cluster of logical organized devices that function as an identity kit for a frame" ( $p$. 64). Such framing devices can be word choice, metaphors, descriptions, arguments, etc., and they are held together by the central organizing theme of the frame. The frame package is completed by the reasoning devices, i.e., explicit and implicit statements that discuss justifications, causes and consequences ( $p .64)$. These reasoning devices are related to the four main elements or functions of a frame, as introduced by Entman (1993): the problem definition of the central issue(s) of the media content and/or critical actors, or causal agents, usually measured in terms of common cultural values; the causal interpretation, or the identification of the forces creating the problem; a positive, negative or neutral moral evaluation of the problem and of the causal agents and their effects; and/or a treatment recommendation, namely a call for, or against, certain actions or treatments to the problem. (Entman, 1993, p. 52; Kohring \& Matthes, 2008, p. 264).

Framing was chosen as a method of analysis as it offers a structured method when seeking to study the different ways a particular issue can be described, especially within media entities such as newspapers. Moreover, it is particularly appropriate when seeking to compare the discourses of sources from different countries, as frames are hereby considered as culture-specific. The following chapter explains the methodological choices and describes the design of the framing analysis.

\section{Methodology}

The identified frames were described on the basis of the main frame elements as discussed above. However, the dimension of causal interpretation was not included in the categorization, because the RTBF was introduced by the EU within the GDPR as proposed in 2012. Therefore, the origin of the issue at hand is not a matter of interpretation, but rather an objective fact. The treatment recommendation was also not applicable to this case as the dimension usually refers to a policy recommendation, while in this situation the RTBF already represents a part of a policy. As a result, the categories of problem definition and moral recommendation were taken to define the frames within this study. Moreover, these two categories were integrated with Radulova's (2009) equivalent of moral recommendation, i.e., what she calls normative dimension. This dimension is introduced as a separate one as it refers to the underlying values of each frame, or the type of values that are needed to consider the issue at hand as a problem (Radulova, 2009, p. 4). The inclusion of such a dimension is crucial when discussing the RTBF as different values stand inevitably behind every different interpretation of the concept.

Recurring framing and reasoning devices were traced to form a preliminary framing scheme, with the identified frames in the rows and three framing dimensions of problem definition, moral evaluation and normative dimension in the columns. This is done with the objective of comparing the frames derived from

\footnotetext{
4 \begin{tabular}{l|l} 
Marble \\
Research \\
Papers
\end{tabular}

Papers
} 
the literature with those subsequently reconstructed from the data analysis. The recurrence of the identified frames within the literature was not thoroughly analyzed, as it went beyond the scope of this study. Rather, a perspective was considered as a frame even if discussed by only one unit of research (see section 2.2.3). This is because the scope of this identification was merely to provide an initial overview of the possible ways to frame the RTBF. Table 1 presents the six frames inductively identified from the literature together with their three main elements. These are threat to free speech, right to privacy, "right to erasure," right to identity/personality ("right to oblivion"), territoriality, and restraint on free enterprise.

In order to gain a more complete overview of how different newspapers framed the RTBF, one high-brow "broadsheet," and one "tabloid" middle-market newspaper was chosen for each country. Among the top 10 major newspapers at the national level, these criteria led to the selection of Il Corriere della Sera (hereafter, Corriere), The Times, and The New York Times (hereafter, NY Times) as the "quality press". The newspapers Quotidiano Nazionale (hereafter, QN), which groups Il Resto del Carlino, Il Giorno and La Nazione (in order of decreasing circulation), The Daily Mail and USA Today were chosen as the middle-market press. The three newspapers of QN were taken as the whole group as they share the main content but differ in the local section. Therefore, the articles on the RTBF were mostly shared in the common part as not representing local news.

The time-frame selected was from 2010 until April 2018 included, as the first proposal of the GDPR was published in 2012, but talks about a possible introduction of the RTBF began to appear in news content as soon as 2010. A total of 139 articles were selected from the LexisNexis database. The frames that were inductively derived (Table 1 ) were taken as a starting point to identify the frames within the articles. This is a deductive strategy. However, the news content was also carefully analyzed in order to inductively reconstruct new, possible frames that were not traced in the literature, and/or frames similar to those derived in the literature, but characterized by slightly different frame packages. The term "reconstruction" is thus hereby used to refer to the mixture of deductive and inductive research strategies employed when examining the news articles.

The software ATLAS.ti was used in order to facilitate the process of data analysis. Each article was coded in qualitative content analysis, manually selecting quotations and assigning them to a total of 33 codes. Analysis of the news articles resulted in the final identification of three frames which were substantially present, two in a medium way, and two minor ones. The frame packages were represented once again in a matrix, with the frames in the rows and the framing and reasoning devices in the columns. Table 2 presents the seven frame packages as characterized by their problem definition, moral evaluation, and normative dimension. The frames are put in descending number of quotations per (grouping of) $\operatorname{code}(\mathrm{s})$. 
Table 1: Framing matrix of the inductively-derived frames from the literature

\begin{tabular}{|c|c|c|c|c|}
\hline $\begin{array}{l}\text { FRAMES / } \\
\text { FRAME } \\
\text { DIMENSIONS }\end{array}$ & $\begin{array}{l}\text { Constitutive } \\
\text { dimension / } \\
\text { problem definition } \\
\text { (What is the } \\
\text { problem?) }\end{array}$ & $\begin{array}{l}\text { Moral } \\
\text { evaluation } \\
\text { (How is the } \\
\text { problem } \\
\text { morally } \\
\text { evaluated?) }\end{array}$ & $\begin{array}{l}\text { Normative } \\
\text { dimension } \\
\text { (Which values } \\
\text { are needed in } \\
\text { order to see this } \\
\text { as a problem / } \\
\text { underlie one's } \\
\text { perception of } \\
\text { social reality?) }\end{array}$ & Authors \\
\hline $\begin{array}{l}\text { (F1) Threat to free } \\
\text { speech }\end{array}$ & $\begin{array}{l}\text { RTBF hinders freedom } \\
\text { of expression and/or } \\
\text { goes against the First } \\
\text { Amendment }\end{array}$ & Negative & $\begin{array}{l}\text { Freedom of } \\
\text { expression is one of } \\
\text { the ultimate human } \\
\text { rights, and has } \\
\text { primacy over right } \\
\text { to privacy }\end{array}$ & $\begin{array}{l}\text { Larson III } \\
\text { (2013), Rosen } \\
\text { (2011) }\end{array}$ \\
\hline (F2) Right to privacy & $\begin{array}{l}\text { RTBF embodies and } \\
\text { defends the right to } \\
\text { privacy, aiming at } \\
\text { protecting the private } \\
\text { sphere and personal } \\
\text { information, which is } \\
\text { liable to infringe a } \\
\text { person's privacy if } \\
\text { published online }\end{array}$ & Positive & $\begin{array}{l}\text { Privacy is one of } \\
\text { the ultimate human } \\
\text { rights, and is equal } \\
\text { if not more } \\
\text { important than } \\
\text { freedom of speech }\end{array}$ & $\begin{array}{l}\text { Xanthoulis } \\
(2013)\end{array}$ \\
\hline $\begin{array}{l}\text { (F3) "Right to } \\
\text { erasure" }\end{array}$ & $\begin{array}{l}\text { RTBF represents the } \\
\text { right for a data } \\
\text { subjects to remove } \\
\text { their personal data } \\
\text { they have released } \\
\text { online; "active data } \\
\text { sharing" }\end{array}$ & Neutral/positive & $\begin{array}{l}\text { Data subjects } \\
\text { should have the } \\
\text { right to revoke } \\
\text { consent to the } \\
\text { processing of their } \\
\text { personal data; } \\
\text { power should be } \\
\text { shifted between } \\
\text { data users and } \\
\text { controllers }\end{array}$ & $\begin{array}{l}\text { Ambrose \& } \\
\text { Ausloos } \\
(2013)\end{array}$ \\
\hline $\begin{array}{l}\text { (F4) Right to } \\
\text { identity/personality; } \\
\text { "right to oblivion" }\end{array}$ & $\begin{array}{l}\text { RTBF allows people } \\
\text { "be different from the } \\
\text { ones we were before" } \\
\text { and to preserve } \\
\text { individual integrity, } \\
\text { reputation, identity, } \\
\text { dignity; "passive data } \\
\text { sharing" }\end{array}$ & Positive & $\begin{array}{l}\text { People should have } \\
\text { their online } \\
\text { reputation and } \\
\text { dignity protected }\end{array}$ & $\begin{array}{l}\text { Ambrose \& } \\
\text { Ausloos } \\
\text { (2013), } \\
\text { Chelaru \& } \\
\text { Chelaru } \\
\text { (2013), De } \\
\text { Andrade } \\
\text { (2014), } \\
\text { Weber } \\
\text { (2011), Werro } \\
\text { (2009) }\end{array}$ \\
\hline (F5) Territoriality & $\begin{array}{l}\text { RTBF violates the } \\
\text { principle of } \\
\text { sovereignty and of } \\
\text { legal national } \\
\text { boundaries by seeking } \\
\text { to extend delinking to } \\
\text { all of Google's global } \\
\text { search sites }\end{array}$ & Negative & $\begin{array}{l}\text { National boundaries } \\
\text { should be } \\
\text { respected when } \\
\text { implementing } \\
\text { legislation }\end{array}$ & Floridi (2015) \\
\hline $\begin{array}{l}\text { (F6) Restraint on free } \\
\text { enterprise }\end{array}$ & $\begin{array}{l}\text { Implementing the } \\
\text { RTBF will place } \\
\text { significant practical } \\
\text { burdens on (US) } \\
\text { businesses such as } \\
\text { search engines and } \\
\text { social networks, which } \\
\text { will significantly } \\
\text { restrain their freedom } \\
\text { to do business in their } \\
\text { own way }\end{array}$ & Negative & $\begin{array}{l}\text { Free enterprise is a } \\
\text { right of paramount } \\
\text { importance: } \\
\text { companies should } \\
\text { decide for } \\
\text { themselves how to } \\
\text { conduct their } \\
\text { business }\end{array}$ & Bernal (2014) \\
\hline
\end{tabular}

Source: The author

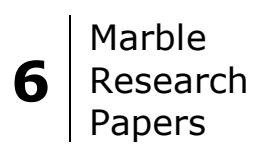


Table 2: Framing matrix of the reconstructed frames from the newspaper articles

\begin{tabular}{|c|c|c|c|}
\hline $\begin{array}{l}\text { FRAMES / } \\
\text { FRAME DIMENSIONS }\end{array}$ & $\begin{array}{l}\text { Constitutive dimension / } \\
\text { problem definition (What is } \\
\text { the problem?) }\end{array}$ & $\begin{array}{l}\text { Moral } \\
\text { evaluation } \\
\text { (How is the } \\
\text { problem } \\
\text { morally } \\
\text { evaluated?) }\end{array}$ & $\begin{array}{l}\text { Normative dimension } \\
\text { (Which values are } \\
\text { needed in order to } \\
\text { see this as a problem } \\
\text { / underlie one's } \\
\text { perception of social } \\
\text { reality?) }\end{array}$ \\
\hline $\begin{array}{l}\text { (F1) Right to access } \\
\text { information } \\
\text { - Need to remember } \\
\text { - Unjust "right to } \\
\text { oblivion" of the past / } \\
\text { erasure of history } \\
\text { - Right to know / } \\
\text { transparency } \\
\text { - Unjust deletion of } \\
\text { crimes }\end{array}$ & $\begin{array}{l}\text { RTBF allows for an erasure of } \\
\text { history and of truthful and } \\
\text { legitimate information belonging } \\
\text { to the past (e.g. of past criminal } \\
\text { convictions and past news } \\
\text { articles), limiting the right to know } \\
\text { and the need for transparency }\end{array}$ & Negative & $\begin{array}{l}\text { People have the right, } \\
\text { duty and need to } \\
\text { remember past events, } \\
\text { individually and } \\
\text { collectively to keep a } \\
\text { record }\end{array}$ \\
\hline $\begin{array}{l}\text { (F2) Right to produce } \\
\text { information }\end{array}$ & $\begin{array}{l}\text { RTBF limits the right to free } \\
\text { speech and represents a form of } \\
\text { censorship, legitimizing cases of } \\
\text { the latter such as in China, and a } \\
\text { threat to press freedom }\end{array}$ & Negative & $\begin{array}{l}\text { Free speech is one of } \\
\text { the ultimate human } \\
\text { rights and trumps over } \\
\text { the right to privacy }\end{array}$ \\
\hline $\begin{array}{l}\text { (F3) Abuse of power } \\
\text { - Abuse by the } \\
\text { rich/powerful } \\
\text { - Airbrush one's personal } \\
\text { history } \\
\text { - Power to delete } \\
\text { information wrongly } \\
\text { given to } \\
\text { people/enterprises } \\
\text { - Unjust deletion of } \\
\text { crimes }\end{array}$ & $\begin{array}{l}\text { RTBF gives unjust power to both } \\
\text { individuals and businesses. It } \\
\text { leads to abuse by the rich and } \\
\text { powerful (such as politicians) } \\
\text { allowing them to airbrush their } \\
\text { past, and wrongly gives power to } \\
\text { both people and search engines } \\
\text { (such as Google) to delete } \\
\text { information }\end{array}$ & Negative & $\begin{array}{l}\text { No one should have the } \\
\text { power to delete } \\
\text { information (be it about } \\
\text { themselves or others), } \\
\text { online or not }\end{array}$ \\
\hline $\begin{array}{l}\text { (F4) "Right to } \\
\text { erasure" }\end{array}$ & $\begin{array}{l}\text { RTBF allows to erase inaccurate, } \\
\text { irrelevant, or inadequate } \\
\text { information and to delete } \\
\text { sensitive, embarrassing or } \\
\text { inadequate information considered } \\
\text { as such by the individual }\end{array}$ & Neutral & N/A \\
\hline $\begin{array}{l}\text { (F5) Right to privacy } \\
\text { and to } \\
\text { identity/reputation } \\
\text { - Right to privacy } \\
\text { - Identity / reputation } \\
\text { - "Revenge porn" }\end{array}$ & $\begin{array}{l}\text { RTBF protects the right to privacy } \\
\text { and the right for individuals, to } \\
\text { have their identity and reputation } \\
\text { preserved }\end{array}$ & Positive & $\begin{array}{l}\text { The right to privacy is } \\
\text { as important as the } \\
\text { right to free expression. } \\
\text { Anyone has the right to } \\
\text { be forgotten for past } \\
\text { mistakes, and not to } \\
\text { have his or her } \\
\text { reputation ruined }\end{array}$ \\
\hline (F6) Territoriality & $\begin{array}{l}\text { RTBF, by being applied on a global } \\
\text { level, goes counter the principle of } \\
\text { national sovereignty and of } \\
\text { respect of national legal } \\
\text { jurisdiction }\end{array}$ & Negative & $\begin{array}{l}\text { One country should not } \\
\text { have control over what } \\
\text { information people in } \\
\text { other countries have } \\
\text { access to. The } \\
\text { Westphalian notion of } \\
\text { sovereignty should be } \\
\text { respected }\end{array}$ \\
\hline $\begin{array}{l}\text { (F7) Attack to US } \\
\text { technology companies }\end{array}$ & $\begin{array}{l}\text { The EU wrongly forces US } \\
\text { technology companies, in } \\
\text { particular search engines (such as } \\
\text { Google) to abide by its RTBF } \\
\text { ruling. This affects and limits the } \\
\text { normal conduct of business of } \\
\text { such US enterprises in a negative } \\
\text { way. The EU says Google has to } \\
\text { take responsibility of its search } \\
\text { results }\end{array}$ & Negative & $\begin{array}{l}\text { American businesses } \\
\text { should not be limited / } \\
\text { "attacked" by the EU } \\
\text { and its decisions, but } \\
\text { should rather be subject } \\
\text { to national US } \\
\text { legislation. Pride for } \\
\text { national businesses }\end{array}$ \\
\hline
\end{tabular}

Source: The author. 


\section{Analysis of the empirical data}

This chapter presents the results of the coding of the news articles. The reconstructed frames are separately discussed and analyzed in order of decreasing quotations. Figure 1 presents the dispersion of the frames across the total number of quotations for all selected newspapers.

Figure 1: Dispersion of the reconstructed frames across the total number of quotations for all newspapers

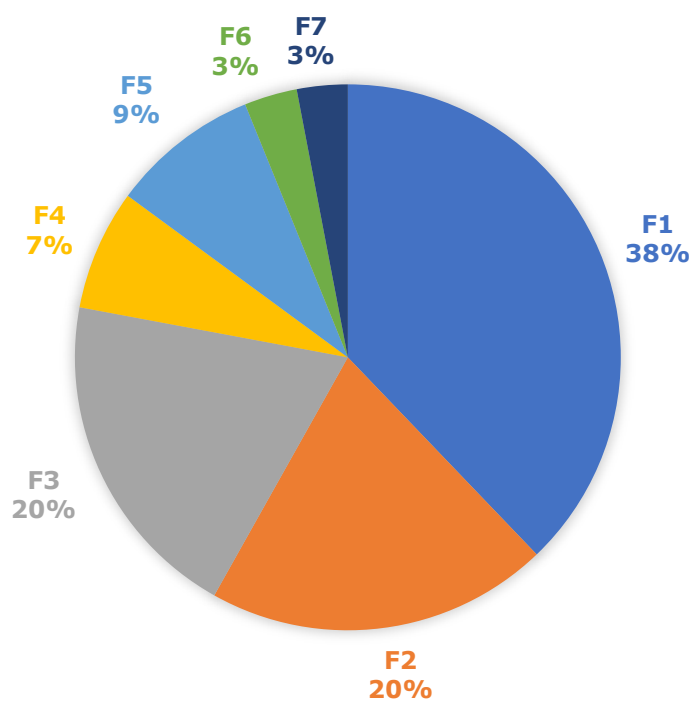

\section{1 (F1) Erasure of history which should be remembered: accessing information}

F1 is the most used frame for all newspapers except for The NY Times, representing half of the total quotations. Its main underlying claim is that the RTBF allows deleting information belonging to the past, truthful records that should not be erased but instead remembered by being kept online. On average $70 \%$ of the quotations for the Italian newspapers belong to this frame, making it the selected country that depicts the RTBF in such a way the most. F1 is composed of four interconnected parts.

The first sub-frame was the most common for all countries and newspapers. It is used within F1 the most by Daily Mail and the UK in general. The RTBF is hereby conceptualized as a tool that allows history to be deleted from the web, i.e., any type of past information regarding either individuals or a collectivity. Concerning the past in general, reference is made to "erase", "delete", "redact", "rewrite", "censor", "sanitize", "freeze" the history "of yesterday and today", or the past; to "altering the historical record(s)", "an internet riddled with memory holes". The RTBF is often compared to a "rubber of History." This fear of such a risk is present quite consistently and without big differences throughout the newspapers. The argument goes that since this was and is not possible, nor accepted, with printed historical records, it should not be allowed also with information published online. Sideri writes for Corriere in April 2018, citing Oscar Wilde, that no one is rich enough to be able to recover/regain the past. Today, this has been widely denied by technology. A metaphor used a few times by both UK newspapers and Corriere compares the RTBF to "going into libraries and burning books you don't like," to "marching into a library and forcing it to pulp books."

The $19 \%$ of all quotations concern the personal history of individuals, and especially criminals. On average half of the quotations within F1 for USA Today, The Times, and Daily Mail refer to how the RTBF
8 \begin{tabular}{l|l} 
Marble \\
Research \\
Papers
\end{tabular} 
gives an unlawful right for past criminal convictions to deleted. Both the UK newspapers particularly emphasize this way of framing the RTBF (nearly one out of three quotations) by making multiple references to how the right to have their criminal past hidden from online search results was given to cases of, inter alia, a businessman convicted for stalking, a clergyman convicted for sex abuse, an actor who had an affair with a teenager, and a doctor with negative reviews from patients. Both Times and Daily Mail seem to have the intent to have the reader connect the RTBF with violent crime episodes and especially of abuse, and to sensationalize the consequences of the proposed Article 17 of the GDPR.

Italian news articles give more attention to the specific case of terrorists. Episodes of terrorism represent a crucial part of Italian history that should be remembered and not be removed, the claim goes. One out of three quotations for both Italian newspapers indeed refers to F1c, which advances that we have a duty to remember, and a collective right to keep a record of crucial past events such as those related to terrorism. This perspective is nearly absent for UK and US news articles. Both Corriere and QN repeatedly refer to the case of ex-terrorist Roberto Nistri, whose request to delete information related to his past was not accepted by the Italian court and by Google. "Especially because terrorism ... is not gone from our lives, it's necessary to be able to know and to think - the opposite of forgetting", writes Sideri for Corriere in 2016, in an article titled The duty to remember. Episodes of terrorism are referred to as "fragments of historical facts where the duty to remember must prevail" (Corriere, 2018), and which have "historical value". Both Corriere and QN defend the existence of both a collective right to build and preserve a collective memory of a society, and of a more general need to remember "even the missteps, the defeats, the griefs, while leaving scars that will never heal" as it is crucial for our personal growth and an integral part of who we are.

The theme of this (collective) need to remember is intrinsically connected to that of the right to know and of information. For this reason, says the argument, the Internet should be and stay transparent. This is the fourth and last sub-frame of $\mathrm{F} 1$, representing the $7 \%$ of all quotations. Once again, Italian newspapers adopt this frame more than the rest, but without major differences with the other press. According to a 2014 Corriere article, the RTBF causes an actual distortion of knowledge, given that Google has become an instrument of information and collective memory. Few articles denounce possible risks of the RTBF by referring to as a loss of "legitimate and truthful information," which should be available for all web users.

\section{2 (F2) Threat to free speech and censorship tool: producing information}

F2 originally corresponds to the most traced frame in the literature (threat to free speech). Within this analysis, instead, it represents the $28 \%$ of the total quotations. F2 was mostly reconstructed from UK and US news articles, and is composed of three main interconnected arguments.

The first sub-frame represents $65 \%$ of F2 quotations and $18 \%$ of the total quotations. It is significantly present in articles of the UK and US quality newspapers, i.e., Times and NY Times. The advanced argument by such press is that the RTBF would "come at a cost to", "infringe", "impair", "be a danger for", "have serious adverse implications for", "be a massive blow to", "significantly restrict", or "pose a threat to" free speech as protected under the US First Amendment. ${ }^{3}$ Articles within F2a define freedom of expression as, inter alia, "one of the fundamentals of democratic society," but especially as "a bedrock American value." The RTBF is framed in such a way that "the US Constitution's commitment to

\footnotetext{
${ }^{3}$ The First Amendment states: "Congress shall make no law respecting an establishment of religion, or prohibiting the free exercise thereof; or abridging the freedom of speech, or of the press."
} 
freedom of speech" is depicted as inherently at odds with and attacked by the proposed Article 17 of the GDPR.

Interestingly, Times articles repeatedly defends the American values and presents opinions of US experts in the field. Aaronovitch writes in a 2016 article titled The creeping advance of privacy rulings appeals to many Europeans but denies the American values that we live by, that "First Amendment rights should trump others, such as those to privacy .... Freedom of speech [is] the primary safeguards against secrecy, abuse of power and tyranny". Italian articles frame the RTBF very little in relation to free speech (16 quotations for Corriere and only 4 for QN) - and when they do, they rather refer to the right of reporting and to criticize, to freely conduct historical research. History is thus, once again, the most prominent in the Italian discourse. In sum, framing the RTBF in such a way differs from the previously discussed association with a right to access information, as F1a concerns and criticizes more the side of the "controller", i.e. Google and/or governments/institutions, for limiting the freedom of expression of the web page publisher, rather than the loss of the people's right to knowledge.

Apart from statements in defense of the US, the majority of UK articles do not refer much to free speech. Instead, they choose to describe how the RTBF is bringing Google to begin a new "regime" or "era of Internet censorship," to "build a complex censorship engine," or having to face "escalating demands for censorship of search results." The Times defines the RTBF in 2014 as "censorship by the back door." In this context, a moderately recurring reasoning device for NY Times and Daily Mail is how such censorship power entailed by the RTBF "encourage repressive regimes intent on internet censorship" (Daily Mail, 2014), or "lends legitimacy to countries like China, Turkey, Iran or Russia that have long controlled what information their citizens can view online" (NY Times, 2016). The RTBF is a tool that ends up controlling "what people around the world get to see on the Internet," just like the states mentioned above impose limits on what content is accessible on search engines. Moreover, this could also subsequently lead officials from those countries to feel "emboldened to demand that Internet companies remove links and material they don't like" from search results.

The third and last sub-frame sees the RTBF as censoring the press in the specific. Freedom of speech does not only concern individuals in their private sphere, but especially the main providers of information: journalists. Within F2c, the strongest claims come from the authors of the news articles themselves, with similar numbers of quotations for UK newspapers and NY Times. They cite, with much outrage, cases concerning precisely each other's press, or other newspapers of the opposite country, where links to past articles were removed because of a request advanced under the RTBF. Mainly because they are speaking about their milieu, the demand to hide "lawful information from a news archive" is strongly criticized by journalists, while the dimension of history or related to individual privacy goes widely in the shade. Once again, Italian newspapers defend the "right of reporting" as a crucial one, and Times defines the RTBF as "the right to regulate perfectly responsible journalism."

\section{3 (F3) (Abuse or misuse of the) unlawful power of information deletion}

F3 represents the $27 \%$ of all quotations. The two UK newspapers are the ones that frame the RTBF in such a way the most, followed by Corriere. F3's central tenet is indeed that the RTBF gives the possibility and unique power to humans to delete information, which is considered as inherently wrong in itself. Most importantly, the fear expressed is that the right "will be misused by those to want to hide their past" (Times, 2014). F3 is composed of four sub-frames.

Within F3, the power to delete information is depicted as being exploited by, first, ex-criminals

(F3a). As this sub-frame was already extensively analyzed in section 5.1 (F1b), it is sufficient to state that
Marble
10 Research
Papers 
the RTBF is hereby attacked for delivering to the hand of criminals a powerful tool to re-define their past and make the world forget about their wrongdoings. F3b depicts the RTBF as more generally allowing individuals to "airbrush", "whitewash", "tailor", "cleanse" or "suppress details of" their life-story, Curriculum Vitae, reputation, or personal history; to "go in with a virtual black marker and redact their names", "rewind the movie of [their] life, omitting the nasty bits", "Photoshop" or "manipulate their own image to make it more to their liking." This is depicted as an unnatural process and human ability because of the very nature of the relationship between people and their life-story, i.e., the former cannot have control and change parts of the latter.

The power to "airbrush one's own story" is criticized not only in general or in relation to criminals, but also by specifically referring to the "rich," "wealthy" and "powerful," and the additional power thereby conferred to them by the RTBF. F3C is once again prominent only for UK newspapers, and slightly more for Times. The fear and risk that the RTBF could be abused is expressed in relation to "(corrupt) politicians", "governments", "corporations", "celebrities", "high-profile individuals" and to how they could "attempt to put pressure ... on search engines to extirpate inconvenient truths" (Daily Mail, 2014) or to "launder their digital historical records." Therefore, F3c does not discuss a possible abuse of power exclusively in relation to crimes or wrongdoings. The focus is rather put on how dangerous it would be to give such a tool in the hands of already powerful, and especially public, figures. This would go against the public interest of the population, as information regarding such figures is one that "the public has a right to know about" (Times, 2016).

The fourth and last sub-frame (F3d) is nearly exclusively traceable within NY Times articles. This refers still to power to delete information stemming from the RTBF, but this time unlawfully conferred to, first, Google specifically and, second, to humans in general. First, the claim is that search engines should not be given the "role" or the "power" to decide "what information is relevant" or "which of the deletion requests are legitimate." "It's not up to a company to make that decision," writes NY Times in 2015. Along the same lines, Danna reports for Corriere in 2014 that "[p]roviding Google with the power to decide which links can be removed is a serious mistake." Second, the RTBF is claimed to be the manifestation of the current "will of individuals" to edit "what's out there in the world." "In the past that's not a responsibility we felt we had," writes Manjoo for NY Times in 2015. Daily Mail defines the RTBF as "terrifying" as "it threatens to empower everyone with a guilty secret to hide" (2014).

\section{4 (F4) "Right to erasure": the neutral definitional frame}

This frame represents the $12 \%$ of the quotations identified. Numbers are similar for the UK newspapers and USA Today while the Italian newspapers have very low quotations related to F4. The RTBF is hereby seen under a neutral perspective. It is defined as the "right to erasure," and precisely in the same ways the EU and CJEU have referred to the RTBF, without any additional devices or techniques to comment on the nature of the concept.

In the first sub-frame (F4a), news articles that frame the notion in such a way indeed limit themselves to citing the ruling of the CJEU in the case of Google Spain v Mario Costeja Gonzalez (CJEU, 2014). The case concerned a Spaniard who requested a Spanish newspaper, and subsequently Google, to remove from online search results the record of the repossession and auction of his house dating back to 1998. The CJEU's ruling was groundbreaking in that it actually decided in favor of the RTBF for the first time, and consequently led to an intense debate both in academic and public discourses.

When writing that "search engines must delete links to items that are 'inadequate, irrelevant or no longer relevant, or excessive in relation to the purposes for which they were processed and in the light of the time that has elapsed'", news articles thus chose to merely follow the CJEU ruling (CJEU, 2014, para 
92-94) in order to describe the RTBF. Only Italian newspapers lack quotations for F4a. Interestingly, articles that cite the exact wording of the CJEU ruling do not frame the RTBF in a particularly positive or negative way after using such wording. The RTBF is merely defined according to the "official way" (of the time) and neither defended nor criticized.

News pieces define the RTBF as a "right to delete" in a neutral way also when describing it as the right to delete "sensitive", "embarrassing", "unflattering" "inconvenient", "debilitating"; or "wrong", "outof-date" information. This is the case especially for Times, as F4b represents the $8 \%$ of all its quotations. Once again, news articles that choose to use this definition do not provide a moral evaluation of the notion or an opinion-based commentary. In contrast with F4a, Italian newspapers also describe the RTBF with F4b devices, although only a few times. This can be explained by the nature of Italian discourses within the following frame.

\section{5. (F5) Protection of the right to privacy and personal identity}

F5 is the only one with a positive connotation that was reconstructed from the news articles, mostly present within Italian newspapers, followed by close numbers for the US press. The UK is in stark contrast with both by having only $1 \%$ related to this frame. Lastly, QN represents the newspaper with the most quotations (one out of three) for the first time. In general, the RTBF is hereby supported because it seeks to protect the privacy and reputation of individuals. Two main reasons, or sub-frames, have been identified for such a defense of the RTBF.

The most common reason advanced within F5 is mainly presented by Italian newspapers, namely that the RTBF allows individuals to have their "personal identity," "personal image," "reputation," "dignity" protected (F5a). The basic tenet of F5a that "if you're always tied to the past, it's difficult to grow, to change" (NY Times, 2014). In contrast with F1, therefore, the past is not seen as a crucial part of each individual, which needs to be preserved. Rather, having embarrassing or inappropriate information online about someone's past is "not just humiliating - it wrecks ... chances for employment" (USA Today, 2015), it "could undermine one's sense of honor and standing in society" (NY Times, 2014), it can block any attempt to start again (Corriere, 2017). People should be allowed to be forgotten for their mistakes, to put the past behind them. In sum, everyone has the right to rebuild a life, without the past continuing to condition the present (Corriere, 2013). USA Today refers multiple times in 2015 to a specific case of harmful information uploaded on the web by a third party, i.e., that of "revenge porn"4, which should be accepted to be deleted (when requested) as "intensely personal and emotionally damaging, and [as it] serve[s] only to degrade the victim".

F5b includes to a proper defense of the right to privacy. Although this represents the second biggest frame traced in the literature, it represents alone only the $4 \%$ of total quotations. Contrary to what claimed in the literature, NY Times is the newspaper with the most quotations, followed by QN. To apply the RTBF means to achieve "a global implementation of the fundamental right to privacy," writes NY Times citing the director of a US privacy research group. Within F5b, the information published online is mostly referred to as "personal data." The RTBF represents the "possibility for individuals to 'reset or cancel' their personal data", or the right of any citizen who no longer wants to find on the web [signs] of his biography, his work, his social contacts or his economic activities - in short of any something that ... can talk to others about him, as defined by Corriere. This can indeed represent content detrimental to the privacy of the

\footnotetext{
${ }^{4}$ USA Today defines the phenomenon in 2016 as "when a former spouse or lover posts nude pictures as an act of malice."

\section{Research Papers}


subject, which is described by QN in also as "the right to be left alone." In sum, the right to privacy is hereby considered as corresponding and being embodied by the RTBF.

\subsection{The minor frames: (F6) Territoriality \& (F7) Attack on US technology companies}

These two frames are the only codes that were not categorizable into any bigger code groups. They are both not present within the middle-market newspapers of Italy and UK (i.e., QN and Daily Mail), and have both a much more noticeable present within USA Today news content. In any case, they represent on average the $9 \%$ each of the total US quotations, while both Italy and UK have a mere figure of $2 \%$ for each frame.

At the basis of F6 lays the request advanced by the French Data Authority in 2015 to expand the application of the RTBF also to search results with domains of countries outside of the EU. The EU was attacked for assuming to be "entitled to unilaterally set rules for the entire world," and expecting to "export its new approach to countries like the US." This "would be unconstitutional," writes The Times when quoting US free speech groups, as it would go against the principle of national sovereignty and jurisdiction as introduced by the Peace of Westphalia in 1648. One country should not "make the laws for another country" (NY Times, 2016), especially with the result of then giving "control over what information people in other countries have access to" (USA Today, 2015).

F7 sees the EU on the one side and US technology corporations on the other. Once again, both US newspapers are the major sources that frame the RTBF in such a way. Because the "requests to be forgotten" are to be dealt with by search engines (which means most of the times by Google) USA Today claims that the EU is making "efforts to impede, frustrate, bully and cut down to size America's most powerful technology companies." These have to deal "with strong pushback, suspicion or even animosity" and are "seen as invaders, not innovators." The EU is depicted as "fearing and distrusting [Google's] dominance" (NY Times, 2016), "another aspect of American power that Europe has long resented and regularly worked to frustrate" (USA Today, 2014). Google is therefore taken to represent the successful American business model, of which the EU is said to be "jealous of." In 2016, Aaronovitch of Times goes so far as to claim that this is reflective of a historic sentiment of envy and ungratefulness felt by Europeans towards the US:

Members of the European Parliament ... have come to regard American companies ... with a prurient disdain. Some in Europe have never really forgiven the Americans for being richer than them, for making English the world's top language, for being loud or even for saving the $[\mathrm{m}]$ in the Second World War.

\subsection{Discussion of the findings}

All the frames inductively traced from the literature were in principle found again in the reconstructed ones. They nonetheless differed, in varying degree, in the framing and reasoning devices characterizing each frame, and in particular in the problem definition. This can be seen by comparing Table 1 with Table 3. The reconstructed frames are below identified with " $R$ ", while " $I$ " refers to the frames inductively derived from the literature.

At first glance, F1R (right to access information) seems to correspond to F4I (right to identity/oblivion). However, they substantially differ: the "right to oblivion" in F4I is equated to the right to identity and personality and has a positive connotation, while in F1R "oblivion" is connected to the negative effect of erasure of historical events which should instead be known and remembered. Therefore, the most used frame in the news articles surprisingly results to be a frame that is barely mentioned in the 
literature. F2R (right to produce information) corresponds to F1I (threat to free speech); however, there is no reference to censorship in F1I. F3R (abuse of power) is the only reconstructed frame that was not traced in the literature and was introduced purely from the news articles analysis. F4R (the definitional frame) corresponds to F3I without major differences (the neutral "right to erasure"). F5R (right to privacy and reputation) corresponds to both F2I (privacy) and F4I (right to identity/oblivion), grouping them. However, F5R does not include the "right to oblivion" as F4I does. F6R coincides with F5I (both territoriality), and F7R (attack on US tech companies) with F6I (threat to free enterprise). While territoriality is framed with nearly the same devices both in the literature and in the news articles, F7R frames the RTBF not only as a constraint on the right of businesses to free enterprise (as in F6I) but especially as reflecting the alleged "jealousy" of the EU of US technology companies.

The results for Italy, the UK and the US, and subsequently for quality and middle-market newspapers, are separately analyzed as follows. First, the Italian way of framing was primarily historyoriented, in defense of what are considered essential parts of the national past (F1a), such as terrorism episodes (F1b). The duty and need to remember such past is also emphasized (F1c). For this reason, attention is given to how the RTBF could be misused by individuals wrongly trying to airbrush their (criminal) history (F1b). More space is thus devoted to stories of specific individuals, to philosophical discourses, and less to neutral and definitional ones. At the same time, however, Italian articles are the ones that protect the right to privacy and to identity and reputation the most (F5a). This seems to be a paradox; however, it can be explained by the fact that Italian news claim that personal past should not be deleted mostly concerning criminals and, especially, ex-terrorists (F1b). Concerning other, smaller mistakes, the RTBF is defended as a tool offering the opportunity to preserve our reputation and dignity. Maintaining personal and family standing indeed represents a crucial Italian value.

Second, the results obtained from UK articles went largely against those expected. When assessing similarity, the distribution of quotations along the frames paradoxically results more similar between Italy and the US than between Italy and the UK. The only similarity with Italian newspapers is that most of the focus is put on criticizing how the RTBF could end up being a "rubber of the past" (F1a). This is followed by a strong emphasis on abuse of power (F3); both of these results are however reducible to the same issue, namely, the RTBF allows criminals the unlawful possibility to erase their wrongdoings (F3a). UK newspapers seem very focused on this specific perspective, steering most of the readers' attention towards a specific (and small) part of the population which could abuse of the power of erasing information as entailed by the RTBF. Two other results were particularly surprising. On the one hand, UK articles have framed the RTBF as a threat to free speech (F2a) the most, and more than double than the US. However, they did so mostly referring to "censorship" rather than to a "threat to free speech." On the other hand, only $1 \%$ of UK quotations discuss the RTBF in the context of the right to privacy (F5). Many devices would indeed defend so-called "American values" and what was defined in the literature as the American stance, i.e., strongly in defense of freedom of expression. However, this taking the US side resulted in UK newS content eventually providing more radical claims than the US articles themselves. In sum, the UK discourses proved to be very different from the Italian ones, undermining the very idea of the existence of a "European stance" on the RTBF, on the basis on which Italy and the UK were originally selected as cases.

Third, the results for the US were also quite different from those expected. Quotations for the different frames were more spread out in comparison with the other two countries. Confirming the claim within the literature, US newspapers did frame the RTBF as a threat to free speech (F2a) the most. However, roughly the same space was also devoted to F1a against the deletion of history, although representing only less than a half of the quotations belonging to such frame for Italian and US newspapers.

\section{Marble \\ 14 Research \\ Papers}


Entirely against the expected results is the fact that US newspapers framed the RTBF as embodying the right to privacy nearly as much as Italian ones (F5). However, they differed from Italy in that a right to have "revenge porn" deleted was the primary focus under F5a, without any reference to a right to identity or reputation, or the emphasis was put on the right to privacy in itself (F5a). It can be concluded that US news content instead aimed at offering a diverse picture of the RTBF to their audience, supporting freedom of speech but without only being critical of the notion. Moreover, US newspapers were the only ones with more than $2 \%$ of quotations dedicated to the dimension of territoriality (F6), and to that of defense of free enterprise and of national businesses (F7) which can be said to represent a core American value (up to $10 \%$ for both frames).

Lastly, quality and middle-market newspapers did not display significant differences in framing the RTBF. Interestingly, the two press categories have instead very similar figures of quotations for each frame. If there was a pattern between one type of press, this subsisted only between two newspapers (such as UK and US quality news similarly more present in F2a, but not the Italian one, and US and Italy middlemarket newspapers less present within F3, but not the UK one). Therefore, such claims could not be generalized for the whole two categories. Moreover, there were not noticed substantial differences in the choice of framing and reasoning devices: very critical statements or radical positions were present in articles of both type of newspapers.

\section{Conclusion}

This research sought to analyze how US and European newspapers have framed the RTBF since 2010. Italy and the UK were taken to represent a possible "European" stance. The RTBF was introduced as a multidimensional concept. Six frames were inductively traced in the literature, among which the RTBF is largely framed either as a threat to free speech or as a defense of the right to privacy. In order to compare academic discourses with media ones, 149 articles of six newspapers (two per country, of which one quality and one middle-market) were analyzed and coded in order to reconstruct the frames used to discuss the RTBF by news authors.

The two perspectives of free speech (F2R) and right to privacy (F5R) were neither the sole nor the principal frames reconstructed from the news articles. Second, at first glance, most of the inductively derived frames from the literature appear to be similar to the reconstructed frames. However, the biggest media frame (F1R) did not correspond to any of the perspectives identified in the literature. The suggested transparency frame (see section 2.3) was found to be a crucial part of F1R: Internet should be transparent and all information accessible, in order for past information, in particular, to be known and remembered. Moreover, the "right to oblivion" is conceptualized as embracing the right to identity in the literature (F4I), while it was reconstructed from the news articles as related to such erasure of history (F1R). Media content indeed focused much on the value of preserving past information and less on the definitional debate of "erasure vs. oblivion." Such debate is instead very present in the literature. This can be explained by the fact that, on the one hand, scholarly articles often aim to discuss issues in more technical terms, due to the very nature of academic research and the audience they are intended for.

On the other hand (although seemingly corresponding to the literature frames), the remaining reconstructed frames were found to be generally discussing the RTBF in relation to concepts that resonate more in their readers. These were both in terms of individual conceptions (e.g., abuse of power by individuals, personal identity, private information, right to access and produce information on an individual basis), and collective and connected to society (e.g., press freedom, right to have a collective memory, national sovereignty and defense of national companies). Lastly, it resulted that national cultural traits 
have a stronger impact on media discourses than the type of audience (intellectual or general) they intend to address.

In sum, this study demonstrated that different cultural values influence the way the media frame a particular issue. First, in the Italian intellectual culture, history occupies a central position, in a way that references to crucial historical chapters such as fascism and the terrorist episodes of the 1980s are recurrent in public discourses also in the light of current events. This particular attention to the national historical heritage is also reflected in how Italians understand themselves and their society. Importance is also given to preserving social standing, individual and family reputation. The willingness to remember terrorist episodes, for example, indeed connects to claim that the victims of such episodes should not be forgotten and that their memory should be upheld. ${ }^{5}$ This is indeed reflected in the way Italian newspapers have framed the RTBF.

Second, in the case of the US, Americans are often claimed to have a peculiarly strong sense of national pride and collectivity, especially in comparison to European countries. This is reflected in the protectionist discourse of national enterprises adopted by US newspapers when discussing the RTBF. Third and last, it was not possible to reconstruct a clear "European" stance on the RTBF. The focus put by UK news content on criminality can be reconducted to a conception that sees individuals being "marked for life" for their wrongdoings, having the duty to be punished for them. This could perhaps be connected to the country's Protestant tradition and ethics. In particular, UK discourses on the RTBF were found to display beliefs and values closer to the US than to Italy. The results thus proved for a shared feeling, in the UK, of a stronger bond with the US than with the rest of Europe. The veracity of these hypotheses, and the sociological connection between national cultural values and the way the RTBF is framed, could be investigated more in depth by further studies, perhaps also in connection with Brexit.

In conclusion, the findings proved less for "transatlantic cultural clash," and rather more for cultural differences on a national basis as the crucial factors standing behind the different ways of perceiving and presenting the RTBF.

\footnotetext{
${ }^{5}$ These claims are based on the author's experience and knowledge of the Italian society. 